\title{
Передача электронного возбуждения из органической матрицы в нанокристаллы CdS, полученные методом Ленгмюра-Блоджетт
}

\author{
(C) А.А. Зарубанов ${ }^{1}$, В.Ф. Плюснин ${ }^{2,3}$, К.С. Журавлев ${ }^{1,3}$ \\ ${ }^{1}$ Институт фризики полупроводников им. А.В. Ржанова \\ Сибирского отделения Российской академии наук, \\ 630090 Новосибирск, Россия \\ ${ }^{2}$ Институт химической кинетики и горения им. В.В. Воеводского \\ Сибирского отделения Российской академии наук, \\ 630090 Новосибирск, Россия \\ ${ }^{3}$ Новосибирский государственный университет, \\ 630090 Новосибирск, Россия \\ E-mail: alexsundr@mail.ru
}

(Получена 8 ноября 2016 г. Принята к печати 14 ноября 2016 г.)

\begin{abstract}
Исследованы спектры поглощения света, фотолюминесценции и возбуждения фотолюминесценции нанокристаллов $\mathrm{CdS}$, сформированных методом Ленгмюра-Блоджетт. Идентифицированы особенности спектров поглощения и возбуждения фотолюминесценции, связанные с оптическими переходами в матрице и нанокристаллах. Изучена эффективность переноса электронного возбуждения из органической матрицы в нанокристаллы. Показано, что носители заряда эффективно переходят из матрицы на уровни размерного квантования электрона и дырки нанокристаллов и на акцепторные уровни дефектов в запрещенной зоне нанокристаллов. Обнаружен большой стоксов сдвиг, который обусловлен тонкой структурой экситона (светлый и темный экситоны). Величина сдвига лежит в диапазоне 140-220 мэВ для нанокристаллов радиусом 2.4 и 2.0 нм соответственно.
\end{abstract}

DOI: 10.21883/FTP.2017.05.44414.8412

\section{1. Введение}

В последние годы нанокристаллы (НК) полупроводников типа $\mathrm{A}^{2} \mathrm{~B}^{6}$ интенсивно изучаются из-за их потенциального применения в различных наноэлектронных устройствах. В основном для получения НК используют молекулярно-лучевую эпитаксию и нанолитографию. Относительно более дешевыми и простыми способами получения НК являются методы коллоидной химии и метод Ленгмюра-Блоджетт (ЛБ) [1]. При этом метод ЛБ предполагает наличие твердой органической матрицы, которую при необходимости можно удалить [2]. Органические материалы в совокупности с полупроводниковыми НК перспективны для создания солнечных батарей [3-6]. В таких структурах ключевыми являются процессы передачи электронного возбуждения из органической матрицы в НК [6-11].

Перенос электронного возбуждения из матрицы в НК активно исследовался для НК, находящихся в полупроводниковой матрице [12-15], а также для НК в проводящих органических соединенияx poly [2-methoxy,5-(2-ethylhexyloxy)-1,4-phenylenevinylene] (MEH-PPV) [5,9,16]. В последнем случае наблюдали как перенос электрона или дырки, так и экситона. Перенос электронного возбуждения из органической матрицы ЛБ в НК изучен слабо.

В данной работе для изучения процессов и эффективности переноса электронных возбуждений из органической матрицы в НК были проанализированы спектры поглощения света и возбуждения фотолюминесценции НК до и после отжига матрицы.

\section{2. Образцы и методика эксперимента}

Исследуемые образцы с HK CdS получались методом ЛБ. В качестве подложек использовали сапфир ориентации (1000), на который наносилось 80 монослоев бегената кадмия. Толщина монослоя пленки ЛБ составляет около 2.7 нм. Сульфидирование пленок бегената кадмия проводилось газообразным сероводородом при температуре $22^{\circ} \mathrm{C}$ и давлении $\mathrm{H}_{2} \mathrm{~S} 100$ Tорр в течение 2 ч. В результате взаимодействия бегената кадмия с сероводородом происходило образование $\mathrm{HK} \mathrm{CdS}$, распределенных в диэлектрической матрице бегеновой кислоты (образец „Мatrix“). Матрица ЛБ удалялась термодесорбцией бегеновой кислоты при температурах 150 и $200^{\circ} \mathrm{C}$ (образцы „NC150“ и „NC200“ соответственно) в атмосфере аммиака в течение примерно 2 ч, а на поверхности подложек оставались НК.

Согласно данным просвечивающей электронной микроскопии (ПЭМ) высокого разрешения, приведенным на рис. $1, a$ и $b$, радиус НК в матрице варьируется от 1.0 до $1.9 \mathrm{HM}$, а средний радиус НК равен примерно $1.7 \mathrm{Hм}$. Плотность НК составляет около $10^{11} \mathrm{~cm}^{-2}$. НК занимают около $1 \%$ площади образца. Радиус НК после отжига $200^{\circ} \mathrm{C}$ увеличивается и составляет около $2.5 \mathrm{HM}$ (рис. 2, $a$ и $b$ ).

Измерения спектров фотолюминесценции (ФЛ) и спектров возбуждения фотолюминесценции (ВФЛ) проводились при комнатной температуре с помощью спектрофлуориметра FLS920 с ксеноновой лампой мощностью 450 Вт в качестве источника возбуждающего излучения. Измерения спектров поглощения проводились с помощью спектрометра Acton SP2500 (Princeton 


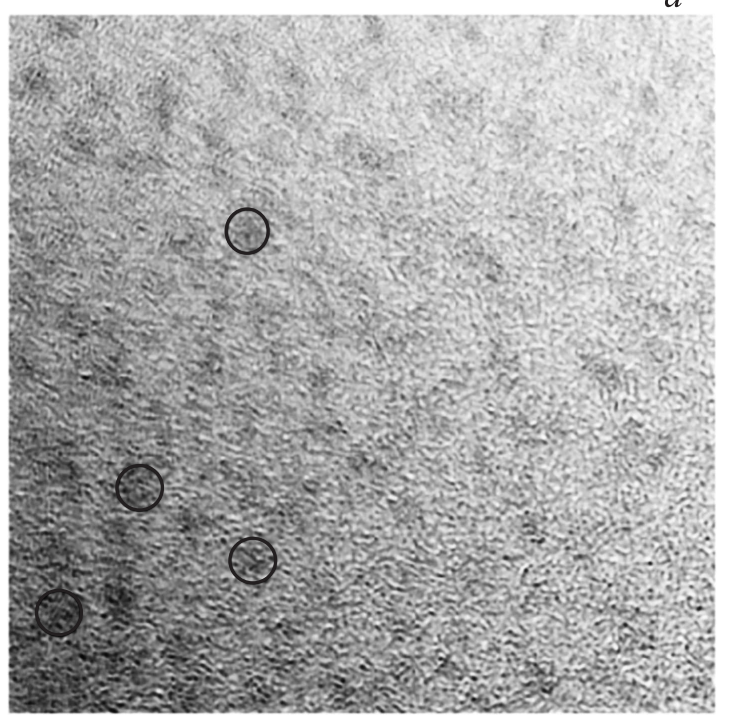

$-5 \mathrm{~nm}$

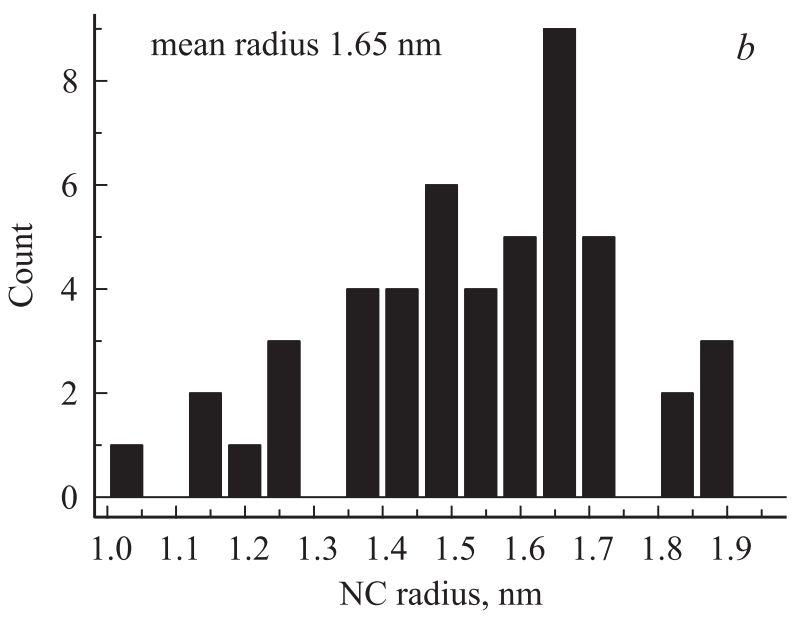

Pис. 1. $a-$ ПЭМ изображение образца с НК $\mathrm{CdS}$ в матрице толщиной 10 монослоев. $b$ - гистограмма распределения НК по радиусу.

Instruments) с регистрацией сигнала CCD-камерой, охлаждаемой азотом. Источником света служила дейтериевая лампа Ocean Optics D1000.

\section{3. Экспериментальные результаты}

На рис. 3 представлены спектры поглощения образцов c HK $\mathrm{CdS}$ в матрице и после ее термодесорбции при температурах 150 и $200^{\circ} \mathrm{C}$. Величина оптического поглощения для всех трех образцов увеличивается с уменьшением длины волны поглощаемого света. При этом в видимой части спектров образцов Matrix, NC150 и NC200 присутствуют пики поглощения в области 365 , 405 и 430 нм, соответственно. Спектр поглощения образца Matrix имеет слабый пик в области 270 нм. В ультрафиолетовой области спектры поглощения имеют пики при 215, 220 и 225 нм для образцов Matrix, NC150 и NC200, соответственно.
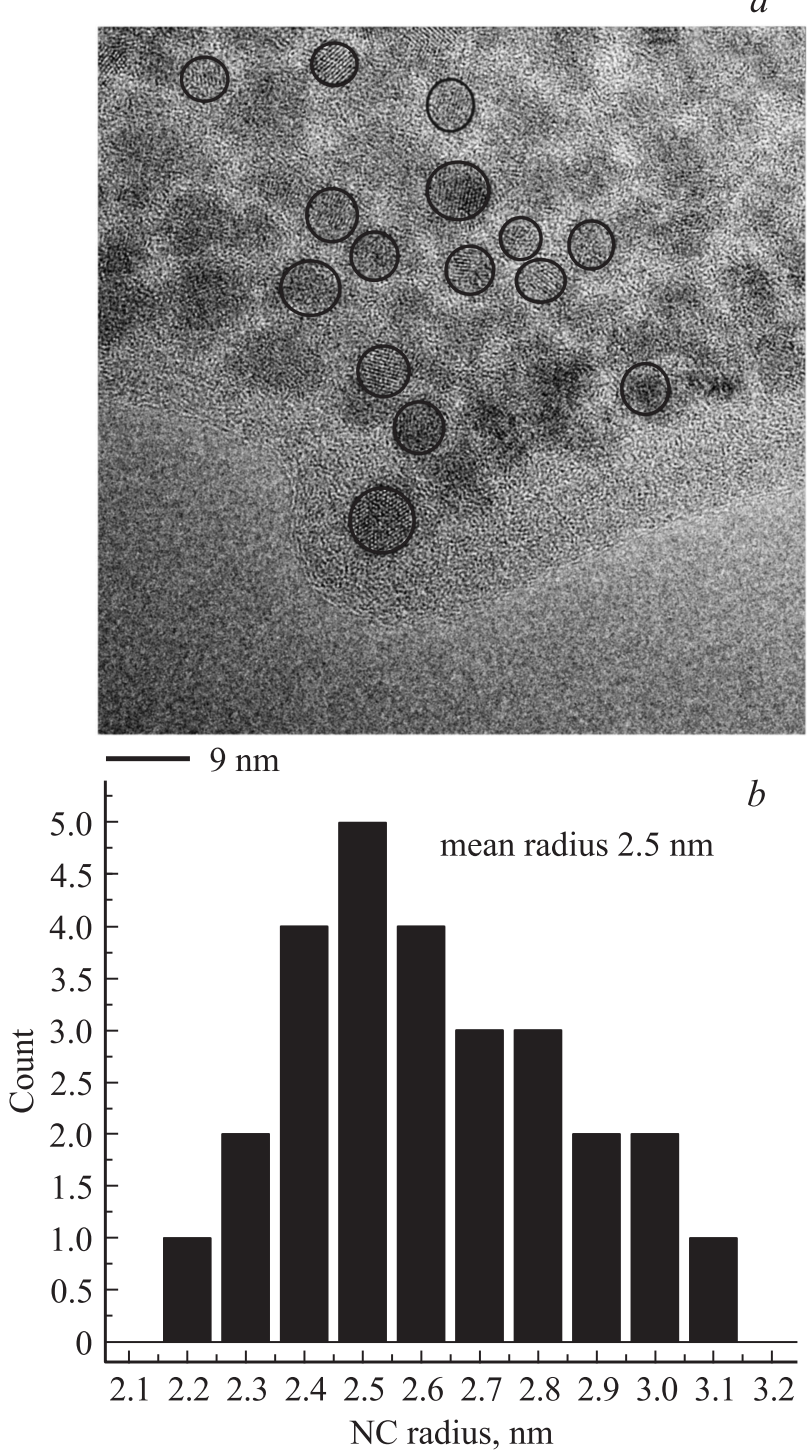

Pис. 2. $a-$ ПЭМ изображение образца с $\mathrm{HK} \mathrm{CdS}$ после отжига $200^{\circ} \mathrm{C}$ толщиной 10 монослоев. $b-$ гистограмма распределения НК по радиусу.

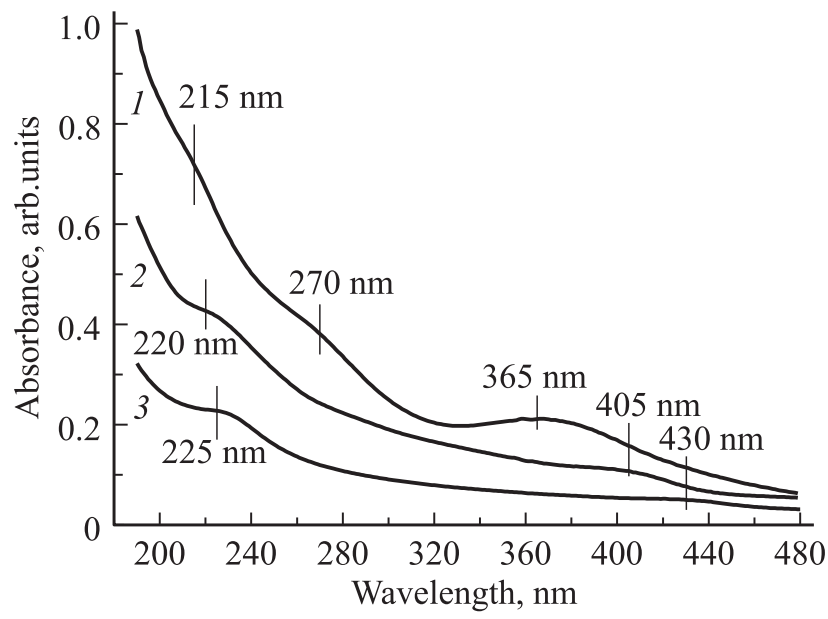

Рис. 3. Спектры поглощения образцов с $\mathrm{HK} \mathrm{CdS}$ на подложках сапфира. НК CdS в матрице (1), НК CdS после термодесорбции матрицы при температурах 150 (2) и $200^{\circ} \mathrm{C}(3)$. 


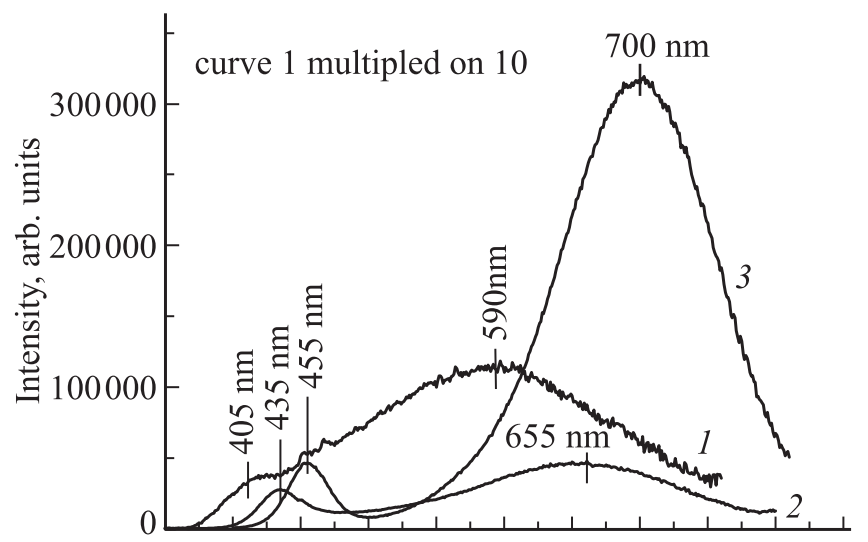

350400450500550600650700750800850 Wavelength, nm

Рис. 4. Спектры ФЛ образцов с НК $\mathrm{CdS}$ на подложке сапфира. Образцы: 1 - Matrix, 2 - NC150, 3 - NC200.
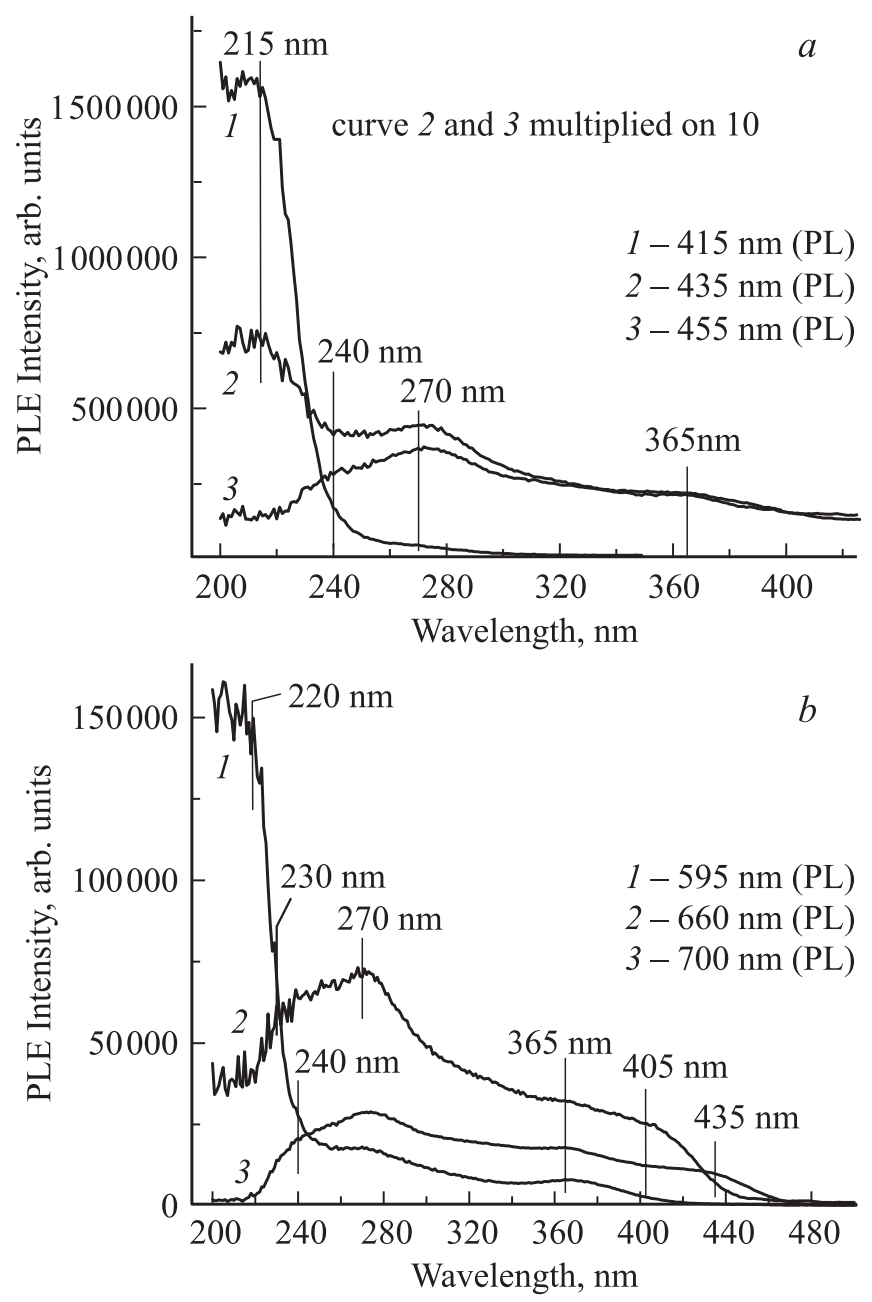

Pис. 5. Спектры ВФЛ образцов с НК CdS: $a$ - для коротковолнового пика ФЛ, $b$ - для длинноволнового пика ФЛ. Образцы: 1 - Matrix, 2 - NC150, 3 - NC200. Точки регистрации фотолюминесценции обозначены сокращением PL.
На рис. 4 представлены спектры ФЛ образцов Matrix, NC150 и NC200. В спектрах ФЛ всех образцов доминирует широкая полоса, занимающая диапазон длин волн $450-800$ нм, и присутствует полоса ФЛ меньшей интенсивности с максимумом 435,455 и около 400 нм для образцов NC150, NC200 и Matrix, соответственно.

На рис. 5, $a$ представлены спектры ВФЛ с энергией регистрации, соответствующей максимуму коротковолнового пика ФЛ. В спектрах ВФЛ всех трех образцов наблюдаются пики с максимумом около 270 нм. В спектрах образцов NC150 и NC200 проявляется дополнительный пик с максимумом около 365 нм. Наибольшие отличия проявляются в коротковолновой части спектров ВФЛ. В спектрах образцов Matrix и NC150 доминирует пик вблизи 215 нм, однако его интенсивность во втором образце значительно меньше. В спектре образца NC200 интенсивность коротковолнового пика еще больше уменьшается, он смещается в красную область спектра и имеет максимум вблизи 240 нм.

Спектры ВФЛ с энергией регистрации излучения, соответствующей максимуму длинноволнового пика ФЛ, представлены на рис. 5, $b$. Интенсивность ФЛ падает по мере уменьшения энергии возбуждающего света. В отличие от спектров ВФЛ коротковолнового пика ФЛ, в УФ области спектра образцов Matrix, NC150 и NC200 положения максимумов ФЛ сдвинуты в сторону бо́льших длин волн и расположены при 220, 230 и 240 нм, соответственно. Интенсивность данных пиков ФЛ падает с увеличением температуры отжига образца. Как и в спектрах ВФЛ коротковолнового пика ФЛ, максимумы при 270 и 365 нм наблюдаются в спектрах всех образцов. В спектрах ВФЛ образцов $\mathrm{NC150}$ и NC200 присутствуют пики в синей области спектра, вблизи 405 и 435 нм, соответственно.

\section{4. Обсуждение результатов}

Коротковолновый пик ФЛ (рис. 4) обусловлен оптическими переходами между уровнями размерного квантования НК [17]. Смещение положения этого пика ФЛ в область длинных волн обусловлено увеличением размера НК с ростом температуры отжига [17]. Положение коротковолнового пика ФЛ связано с размерами НК формулой Брюса, которая учитывает эффект размерного квантования и кулоновское взаимодействие электрона и дырки [18]:

$$
E=E_{g 0}+\frac{\hbar^{2} \pi^{2} n^{2}}{2 m^{*} R^{2}}-\frac{1.8 e^{2}}{4 \pi \varepsilon \varepsilon_{0} R}
$$

где $E$ - энергия между уровнями размерного квантования электрона и дырки, $E_{g 0}=2.48$ эВ - ширина запрещенной зоны объемного $\mathrm{CdS}$ при $T=300 \mathrm{~K}, \hbar-$ постоянная Планка, $n-$ положительное целое число, $m^{*}=m_{e} m_{h} /\left(m_{e}+m_{h}\right)=0.154 m_{0}-$ приведенная масса электрона $\left(m_{e}\right)=0.19$ и дырки $\left(m_{h}\right)=0.8, e-$ заряд электрона, $\varepsilon$ - диэлектрическая проницаемость $\mathrm{CdS}$ 
$(\varepsilon=5.7[18]), \varepsilon_{0}-$ относительная диэлектрическая проницаемость, $R$ - радиус НК. Расчет по формуле (1) показывает, что радиус НК в образцах Matrix, NC150 и NC200 составляет 1.7, 2.0 и $2.4 \mathrm{HM,} \mathrm{соответственно.}$ Согласно данным ПЭМ, средний радиус НК в образце Matrix составляет 1.7 нм, в образце NC200 - 2.5 нм, что подтверждает справедливость сделанной оценки.

Широкий пик ФЛ в длинноволновой области спектра обусловлен рекомбинацией через уровни энергии, лежащие внутри запрещенной зоны НК. Эти уровни могут быть связаны как со структурными дефектами внутри НК, так и с состояниями на границе раздела НК-матрица. На рис. 4 показано положение обоих пиков ФЛ для НК различных размеров. Видно, что оба пика одинаковым образом смещаются в область низких энергий с ростом радиуса НК. Расстояние между этими пиками около 0.95 эВ и не изменяется с изменением размера НК. Известно, что уровень дефекта в НК слабо зависит от размера НК [19], поэтому смещение длинноволнового пика может быть обусловлено смещением уровня размерного квантования, при условии, что происходит переход между уровнем размерного квантования и уровнем дефекта.

На рис. 6 приведены энергии электрона и дырки в НК, рассчитанные согласно формуле (1). Для расчета энергии размерного квантования по формуле (1) вместо приведенной массы электрона и дырки принималось значение эффективной массы электрона или дырки. Видно, что уровень электрона $\left(\Delta E_{e}\right)$ смещается сильнее уровня дырки $\left(\Delta E_{h}\right)$ при изменении размера НК из-за большого различия их эффективных масс $\left(m_{e}<m_{h}\right)$. Более того, видно, что уровень электрона и пики ФЛ смещаются симбатно при изменении размеров НК, следовательно, смещение пиков ФЛ обусловлено изменением энергии электронов.

Электронные переходы между уровнями размерного квантования НК проявляются в видимой области (405-450 нм) спектров поглощения и возбуждения ФЛ длинноволнового пика образцов NC150 и NC200. Отсутствие пика в видимой части спектров поглощения и ВФЛ образца Matrix, обусловленного переходами в НК, объясняется поглощением света по большей части в матрице, очевидно, из-за того, что при сравнимой толщине матрица занимает примерно 99\% площади образца, а НК только около $1 \%$. При отжиге матрица утоняется и(или) уменьшается ее площадь и поглощение в НК становится сравнимым с поглощением в матрице. Уменьшение поглощения в матрице при отжиге, вероятно, происходит в большей степени из-за уменьшения ее площади.

Сравнение положения пиков в спектрах ФЛ и ВФЛ позволяет оценить Стоксов сдвиг, который составляет 140 и 220 мэВ для образцов $\mathrm{NC} 150$ и NC200, со средним радиусом 2.4 и $2.0 \mathrm{HM}$, соответственно. Такой большой стоксов сдвиг обусловлен тонкой структурой экситона, когда поглощение света связано с переходами на уровень светлого экситона, а излучение обусловлено рекомбинацией темного экситона [20]. Ранее для НК

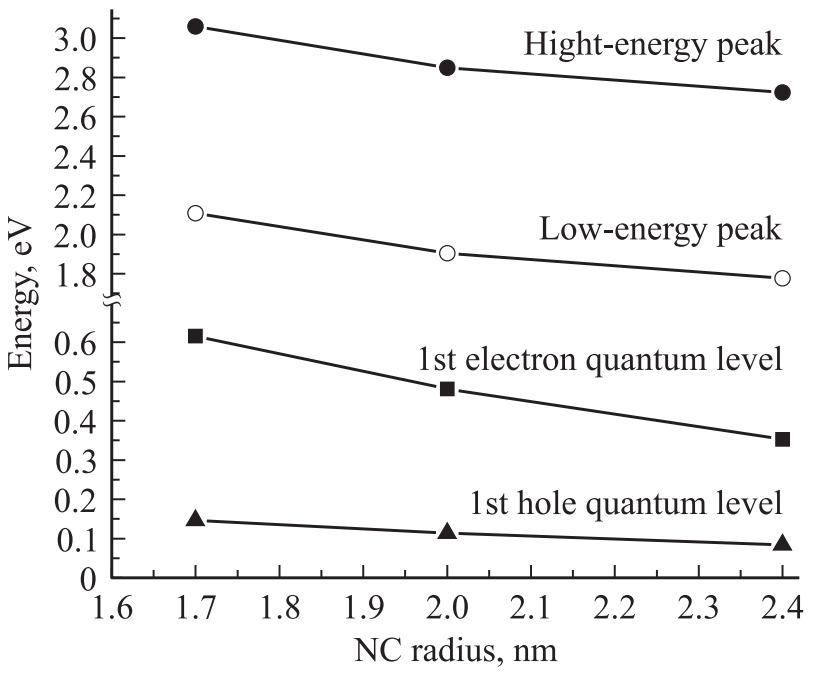

Рис. 6. Зависимость положения пиков ФЛ и уровней размерного квантования электрона и дырки от размера НК.

$\mathrm{CdS}$, полученных методом коллоидной химии, наблюдали сдвиг от 20 до 70 мэВ для НК радиусом 2.0 и 1.3 нм при температуре $10 \mathrm{~K}$, соответственно [20]. Это в несколько раз ниже, чем полученные нами значения. Данное отличие может быть обусловлено влиянием окружения НК [21].

Полосы в УФ области спектров поглощения и ВФЛ (270 нм и в области длин волны 215-240 нм), скорее всего, связаны с поглощением в матрице или остатках матрицы. В пользу такой идентификации говорит то, что в спектрах поглощения сапфира подобные полосы не наблюдались, но присутствовали в спектрах ВФЛ НК на кремниевой подложке. Кроме того, расчет уровней размерного квантования по формуле (1) показывает, что в НК переходы, соответствующие энергиям максимумов данных полос, отсутствуют. Значения энергий переходов между вторыми уровнями размерного квантования электрона и дырки равны 4.0 (305 нм), 4.7 (265 нм) и 5.6 эВ (225 нм) для образцов NC200, NC150 и Matrix, соответственно, что ниже энергии наблюдаемых переходов. Снижение интенсивности коротковолновой полосы в спектрах ВФЛ на порядок при увеличении температуры отжига связано с термодесорбцией матрицы, а сдвиг положения с 215 до 240 нм можно объяснить изменением ее состава. Спектры ВФЛ позволяют достаточно точно оценить ширину запрещенной зоны матрицы исходной пленки ЛБ, она равна 5.8 эВ. После отжига при $200^{\circ} \mathrm{C}$ ширина запрещенной зоны остатков матрицы составляет 5.1 эВ, что согласуется с величиной, полученной в работе [22]. Мы полагаем, что полоса в спектрах ВФЛ около 270 нм связана с состояниями на границе раздела НК-матрица, поскольку отжиг матрицы не сказывается на ее интенсивности, а в спектре НК таких переходов, согласно расчетам, нет. Полоса при 366 нм, вероятно, связана с уровнями в запрещенной зоне матрицы. Об этом свидетельствуют большая интенсивность данной полосы в спектре образца без отжига 


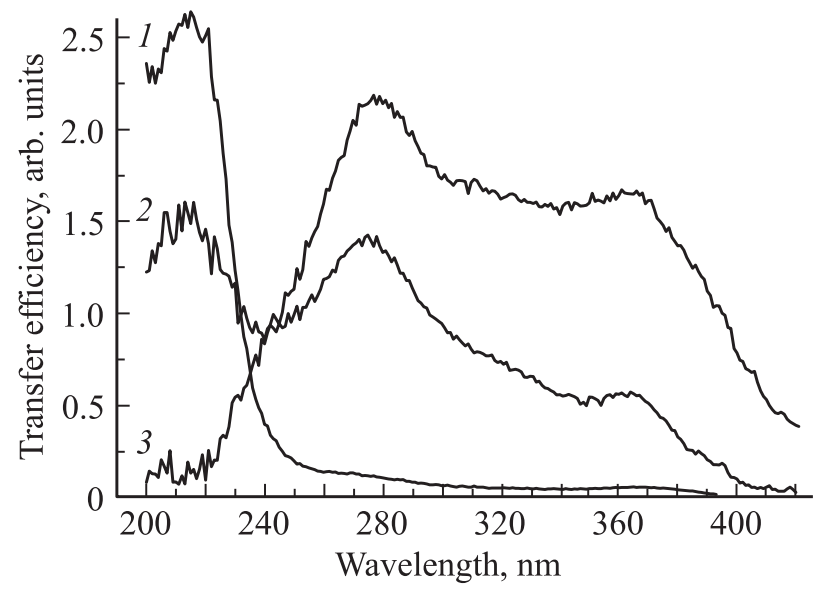

Рис. 7. Спектральная зависимость эффективности передачи электронного возбуждения в НК. Образцы: 1 - Matrix, 2 NC150, 3 - NC200.

и снижение поглощения после отжига относительно поглощения в синей области спектра. Похожая картина наблюдается в спектрах ВФЛ дефектной полосы ФЛ (рис. 5,b). Однако максимумы УФ полос в спектрах образцов Matrix и NC150 сдвинуты в красную область спектра и находятся около 220 и 230 нм соответственно. Природа этих изменений на данный момент не ясна.

Из спектров ВФЛ видно, что $e-h$ пары, генерированные в матрице, захватываются и рекомбинируют в НК. В НК захватываются как $e-h$ пары из матрицы (полоса при 215 нм), так и из состояний на границе НК-матрица (полосы вблизи 270 и 365 нм). В пользу этого свидетельствует большая интенсивность полос, обусловленных поглощением в матрице в спектрах ВФЛ. Сравнение спектров поглощения и ВФЛ позволяет оценить эффективность передачи возбуждения из зонных (215 нм полосы) и дефектных состояний матрицы (270 и 365 нм полосы). На рис. 7 представлена зависимость эффективности передачи возбуждения от длины волны, определяемая как отношение спектров ВФЛ и поглощения. При таком сравнении эффективности передачи из разных состояний матрицы потери на безызлучательную рекомбинацию в НК учитывать не нужно. Из рис. 7 видно, что для образца Matrix эффективность передачи возбуждения из дефектных состояний матрицы в НК меньше, чем из зонных состояний матрицы. Относительная эффективность передачи возбуждения из дефектных состояний матрицы в НК составляет около 5\%. По мере увеличения температуры отжига матрицы эффективность переноса возбуждения из матрицы в НК падает относительно переноса возбуждения из дефектных состояний матрицы. Вероятно, это обусловлено изменением структуры матрицы. Термическая обработка тонких слоев органических полупроводников может вносить изменения в границу разделов слоев и их внутреннюю структуру, что сказывается, в том числе, на люминесценции и приводит к ее тушению [23].
Сгенерированные в матрице носители заряда, попадая в НК, также могут рекомбинировать через уровень акцептора, давая дефектную ФЛ (рис. 5, b). При этом дырка может сразу захватываться на акцепторный уровень либо попасть на этот уровень через уровень размерного квантования дырки в НК. Интенсивность УФ полосы в спектре ВФЛ НК образца Matrix на порядок больше интенсивности аналогичной полосы в спектре ВФЛ дефектной полосы. Это означает, что бо́льшая часть генерируемых в матрице носителей заряда попадает на уровни размерного квантования НК, нежели на акцепторный уровень. При этом доминирующим каналом излучательной рекомбинации является рекомбинация через акцепторный уровень. Учитывая вышеизложенное, можно заключить, что носители заряда из матрицы попадают на уровень размерного квантования, после чего попадают на уровень акцептора и рекомбинируют.

Интенсивности полос вблизи 270 и 365 нм в спектрах ВФЛ НК и дефектной полосы всех образцов имеют примерно одинаковые величины. Более того, в спектрах ВФЛ дефектной полосы образцов NC150 и NC200 полосы, обусловленные состояниями матрица-НК (270 и 365 нм), имеют бо́льшую интенсивность, чем полоса, обусловленная матрицей. Это свидетельствует о том, что неравновесные дырки с дефектных состояний матрицы в большей степени захватываются сразу на акцепторный уровень, затем рекомбинируют с электроном на уровне размерного квантования.

\section{5. Заключение}

В работе исследованы при комнатной температуре спектры поглощения, ФЛ и ВФЛ $\mathrm{HK} \mathrm{CdS}$ в исходной матрице ЛБ и после ее термодесорбции при 150 и $200^{\circ} \mathrm{C}$. Показано, что полоса ФЛ в красной области обусловлена рекомбинацией электрона с уровня размерного квантования и с дыркой на уровне акцептора в запрещенной зоне НК. Установлено, что электронное возбуждение эффективно передается из органической матрицы в НК, однако эффективность переноса возбуждения падает при увеличении температуры термодесорбции изза нарушения структуры матрицы. Обнаружен большой стоксов сдвиг, который объясняется моделью светлых и темных экситонов. Величина сдвига возрастает с уменьшением радиуса НК и для радиуса НК 2.0 нм составляет 220 мэВ. Характер зависимости совпадает с теоретическими и экспериментальными результатами, однако величина сдвига в несколько раз больше ранее обнаруженной. Данный факт может быть объяснен наличием матрицы с конечной величиной относительной диэлектрической проницаемости.

Авторы благодарны Л.Л. Свешниковой за предоставление образцов, А.К. Гутаковскому за предоставленные изображения НК с просвечивающего электронного микроскопа и РФФИ (грант № 17-02-01364) за финансовую поддержку. 


\section{Список литературы}

[1] A. Rauadel-Teixier, J. Leluoup, A. Barraud. Mol. Cryst. Liq. Cryst., 134, 347 (1986).

[2] А.А. Зарубанов, К.С. Журавлев. ФТП, 49 (3), 392 (2015).

[3] D. Baran, A. Balan, S. Celebi, B.M. Esteban, H. Neugebauer, N.S. Sariciftci, L. Toppare. Chem. Mater., 22, 2978 (2010).

[4] K.M. Coakley, M.D. McGehee. Chem. Mater., 16, 4533 (2004).

[5] M. He, F. Qiu, Z. Lin. J. Phys. Chem. Lett., 4, 1788 (2013).

[6] L. Wang, Y. Liu, X. Jiang, D. Qin, Y. Cao. J. Phys. Chem. C, 111, 9538 (2007).

[7] D.J. Milliron, A.P. Alivisatos, C. Pitois, C. Edder, J. Fréchet. Advanced Mater., 15 (3), 58 (2003).

[8] P. Maity, T. Debnath, H.N. Ghosh. J. Phys. Chem. Lett., 4, 4020 (2013).

[9] N.C. Greenham, X. Peng, A.P. Alivisatos, Phys. Rev. B, 54 (24), 17628 (1996).

[10] Sh. Jin, R.D. Harris, B. Lau, K.O. Aruda, V. A. Amin, E.A. Weiss. Nano Lett., 14 (9), 5323 (2014).

[11] P.V. Kamat. J. Phys. Chem. Lett., 4, 908 (2013).

[12] T.S. Shamirzaev, D.S. Abramkin, A.V. Nenashev, K.S. Zhuravlev, F. Trojánek, B. Dzurm̌ák, P. Malý. Nanotechnology, 21, 155703 (2010).

[13] F. Gindele, U. Woggon, W. Langbein, J.M. Hvam, K. Leonardi, D. Hommel, H. Selke. Phys. Rev. B, 60 (12), 8773 (1999).

[14] M. Funato, K. Omae, Y. Kawakami, Sg. Fujita, C. Bradford, A. Balocchi, K.A. Prior, B.C. Cavenett. Phys. Rev. B, 73, 245308 (2006).

[15] P. Maity, T. Debnath, H.N. Ghosh. J. Phys. Chem. Lett., 4, 4020 (2013).

[16] D.S. Ginger, N.C. Greenham. Phys. Rev. B, 59, 10622 (1999).

[17] Е.А. Багаев, К.С. Журавлев, Л.Л. Свешникова, Д.В. Щеглов. ФТП, 42 (6), 718 (2008).

[18] L.E. Brus. J. Chem. Phys. 80, 4403 (1984).

[19] H. Fu, A. Zunger. Phys. Rev. B, 56 (3), 1496 (1997).

[20] Zh. Yu, J. Li, D.B. O'Connor, L.-W. Wang, P.F. Barbara. J. Phys. Chem. B, 107, 5670 (2003).

[21] V.A. Fonoberov, E.P. Pokatilov, A.A. Balandin. Phys. Rev. B, 66, 085310 (2002).

[22] K.A. Svit, K.S. Zhuravlev. J. Phys. Chem. C, 119 (33), 19496 (2015).

[23] M. Fahlman, W.R. Salaneck. Surf. Sci., 500, 904 (2002).

Редактор Г.А. Оганесян

\section{Excitation transfer from organic matrix to CdS nanocrystals fabricated by the Langmuir-Blodgett method}

\author{
A.A. Zarubanov 1, V.F. Plyusnin ${ }^{2,3}$, K.S. Zhuravlev 1,3 \\ ${ }^{1}$ Rzhanov Institute of Semiconductor Physics, \\ Siberian Branch of the Russian Academy of Sciences, \\ 630090 Novosibirsk, Russia \\ 2 Voevodsky Institute \\ of Chemical Kinetics and Combustion, \\ Siberian Branch of the Russian Academy of Sciences, \\ 630090 Novosibirsk, Russia \\ ${ }^{3}$ Novosibirsk State University, \\ 630090 Novosibirsk, Russia
}

Abstract In this paper we studied the absorption, photoluminescence and photoluminescence excitation spectra of CdS nanocrystals formed by the Langmuir-Blodgett technique. Features of the absorption and photoluminescence excitation spectra associated with optical transitions in the matrix and nanocrystals were identified. The efficiency of the transfer of electronic excitation from organic matrix to nanocrystals was studied. It is shown that the charge carriers are efficiently transferred from matrix to the levels of electron and hole and level of acceptor in nanocrystals. The large Stokes shift caused by the fine structure of exciton (light and dark exciton) was measured. The shift value is in the range of $140-220 \mathrm{meV}$ for nanocrystals radius of $2.4 \mathrm{~nm}$ and $2.0 \mathrm{~nm}$, respectively. 